\title{
Biofilm formation by zygomycetes: quantification, structure and matrix composition
}

\begin{abstract}
Correspondence
Arunaloke Chakrabarti

arunaloke@hotmail.com
\end{abstract}

Received 24 January 2011

Revised 12 May 2011

Accepted 26 May 2011

\author{
Rachna Singh, M. R. Shivaprakash and Arunaloke Chakrabarti \\ Division of Mycology, Department of Medical Microbiology, Postgraduate Institute of Medical \\ Education and Research (PGIMER), Chandigarh-160012, India
}

\begin{abstract}
Most studies on fungal biofilms have focused on Candida in yeasts and Aspergillus in mycelial fungi. To the authors' knowledge, biofilm formation by zygomycetes has not been reported previously. In this study, the biofilm-forming capacity of Rhizopus oryzae, Lichtheimia corymbifera, Rhizomucor pusillus and Apophysomyces elegans was evaluated. At appropriate seeding spore densities, Rhp. oryzae $\left(10^{5}\right.$ c.f.u. $\left.\mathrm{ml}^{-1}\right)$, L. corymbifera $\left(10^{4}\right.$ c.f.u. $\left.\mathrm{ml}^{-1}\right)$ and $R$ hm. pusillus $\left(10^{4}\right.$ c.f.u. $\left.\mathrm{ml}^{-1}\right)$ produced highly intertwined, adherent structures on flat-bottomed polystyrene microtitre plates after $24 \mathrm{~h}$ at $37{ }^{\circ} \mathrm{C}$. The adhered fungal hyphae were encased in an extracellular matrix, as confirmed by phase-contrast and confocal microscopy. The thickness of Rhp. oryzae, L. corymbifera and Rhm. pusillus biofilms was $109.67 \pm 10.02,242 \pm 23.07$ and $197 \pm 9.0 \mu \mathrm{m}$ (mean $\pm S D$ ), respectively. Biochemical characterization of the biofilm matrix indicated the presence of glucosamine, constituting 74.54-82.22\% of its dry weight, $N$-acetylglucosamine, glucose and proteins. Adherence and biofilm formation were not observed in $A$. elegans. Although $A$. elegans spores germinated at all three seeding densities tested $\left(1 \times 10^{7}, 1 \times 10^{6}\right.$ and $1 \times 10^{5}$ c.f.u. $\mathrm{ml}^{-1}$ ), no significant difference was observed $(P>0.05)$ between the $A_{490}$ of wells inoculated with $A$. elegans and the cut-off $A_{490}$ for biofilm detection. This study highlights the potential for biofilm formation by at least three medically important species of zygomycetes.
\end{abstract}

\section{INTRODUCTION}

Biofilms are dense, highly hydrated cell clusters that are irreversibly attached to a substratum, to an interface or to each other, and are embedded in a self-produced gelatinous matrix composed of extracellular polymeric substances (EPS) (Harding et al., 2009). The micro-organisms in these biofilms exhibit an altered phenotype with respect to growth rate, gene transcription, and resistance to physical, chemical and biological stresses (Chandrasekar \& Manavathu, 2008; Harding et al., 2009; Mowat et al., 2009). Biofilm formation has been widely implicated in the pathogenesis of implant-associated and chronic infections (Hall-Stoodley et al., 2004).

Most of the work describing biofilm genesis, architecture, chemical composition, genetic regulation and antimicrobial drug resistance has focused on bacteria and yeasts (Chandrasekar \& Manavathu, 2008; Harding et al., 2009; Mowat et al., 2009). Occasionally, filamentous fungi have also been reported to form biofilms (Chandrasekar \& Manavathu, 2008; Harding et al., 2009; Mowat et al., 2009).

Abbreviations: CLSM, confocal laser scanning microscopy; Con-A concanavalin A conjugated to Alexa Fluor; ELLA, enzyme-linked lectinsorbent assay; EPS, extracellular polymeric substance; G6PDH, glucose-6-phosphate dehydrogenase; GlcN, glucosamine; GlcNAc, $\mathrm{N}$-acetylglucosamine; OG, Oregon green; ROC, rhino-orbito-cerebral; WGA, wheatgerm agglutinin.
Although filamentous fungi often penetrate the substrates that they grow on, and this invasive growth may not accurately represent the term biofilm (Harding et al., 2009), the yeasts Candida albicans and Trichosporon asahii have been shown to require differentiation to hyphal forms during biofilm formation (Harding et al., 2009; Ramage et al., 2009). Filamentation in fungi may therefore be a prerequisite for robust biofilm development and virulence, and fungal biofilms perhaps represent much more than a mere biological coating (Harding et al., 2009). Biofilm formation is claimed to be involved in the pathogenesis of localized as well as invasive diseases caused by Aspergillus fumigatus (Beauvais et al., 2007; Chandrasekar \& Manavathu, 2008; Harding et al., 2009; Loussert et al., 2010; Mowat et al., 2007, 20\08, 2009). Aspergilloma, a localized infection, has been shown to consist of highly agglutinated hyphae encased in an extracellular matrix (Loussert et al., 2010; Mowat et al., 2009). A similar exopolysaccharide matrix is also produced at the surface of fungal hyphae during invasive pulmonary aspergillosis (Loussert et al., 2010).

Fungi belonging to the class Zygomycetes and the order Mucorales, including Rhizopus, Rhizomucor, Mucor, Lichtheimia, Apophysomyces, Cunninghamella and Saksenaea, often cause opportunistic infections which are similar to those caused by Aspergillus and are characterized by angioinvasion 
and fungal-ball formation (Chakrabarti et al., 2001, 2006, 2009; Goodnight et al., 1993; Kirkpatrick et al., 1979; Lahiri et al., 2001; Robey et al., 2009). Mucormycosis is categorized into rhino-orbito-cerebral (ROC), pulmonary, gastrointestinal, cutaneous and disseminated types depending upon the clinical presentation and the anatomical sites involved (Chakrabarti et al., 2001, 2006, 2009). While the ROC type is often associated with individuals having uncontrolled diabetes and diabetic ketoacidosis, the pulmonary, gastrointestinal and cutaneous types occur in patients with haematological malignancies or neutropenia, severe malnutrition, and trauma or burns, respectively (Chakrabarti et al., 2001, 2006, 2009). The incidence of mucormycosis has increased globally over the last two decades, with a phenomenal rise in the number of cases reported from India (Chakrabarti et al., 2001, 2006, 2009). Three case series on mucormycosis have been reported from our tertiary-care centre: 129 cases over 10 years (1990-1999), 178 cases during the subsequent five years (2000-2004) and then 75 cases in an 18 month period during 2006-2007 (Chakrabarti et al., 2001, 2006, 2009). Rhizopus oryzae and Apophysomyces elegans (sensu lato) were the predominant isolates in these series (Chakrabarti et al., 2001, 2006, 2009).

Since more than $99 \%$ of microbes have been reported to grow as biofilms, and these surface-attached communities have also been implicated in the pathogenesis of both localized as well as invasive diseases caused by Aspergillus, the present study was planned to elucidate the biofilmforming potential of four common pathogenic zygomycetes: Rhizopus oryzae, Lichtheimia corymbifera, Rhizomucor pusillus and Apophysomyces elegans.

\section{METHODS}

Fungal strains. Rhp. oryzae NCCPF 710004, L. corymbifera NCCPF 700002, Rhm. pusillus NCCPF 720004 and A. elegans NCCPF 102033 were used in this study. The strains were obtained from the National Culture Collection of Pathogenic Fungi (NCCPF), Department of Medical Microbiology, Postgraduate Institute of Medical Education and Research (PGIMER), Chandigarh, India, and were preserved in $20 \%$ glycerol at $-70{ }^{\circ} \mathrm{C}$ until use.

Isolation of sporangiospores. Rhp. oryzae, L. corymbifera and $R h m$. pusillus were grown on Sabouraud dextrose agar (SDA) at $37{ }^{\circ} \mathrm{C}$ for 4-5 days. A. elegans was cultured on water agar at $37{ }^{\circ} \mathrm{C}$ for 7 days. The plates were flooded with $10 \mathrm{ml}$ PBS $(0.1 \mathrm{M}, \mathrm{pH} 7.2)$ and sporangiospores were harvested by repeated washing of the mycelia with the added buffer. The resulting suspensions were centrifuged at 6000 r.p.m. at $4{ }^{\circ} \mathrm{C}$ for $10 \mathrm{~min}$; the pellets were washed twice with PBS and finally suspended in $1 \mathrm{ml}$ PBS. Spores were counted using a Neubauer haemocytometer and counts expressed as c.f.u. $\mathrm{ml}^{-1}$.

Standardization of biofilm formation. Biofilm formation was determined according to the method of Pierce et al. (2008). The spores were adjusted to the required density ( $R h p$. oryzae, $L$. corymbifera and Rhm. pusillus - $1 \times 10^{7}, 1 \times 10^{6}, 1 \times 10^{5}, 1 \times 10^{4}$ and $1 \times 10^{3}$ c.f.u. $\mathrm{ml}^{-1}$; A. elegans $-1 \times 10^{7}, 1 \times 10^{6}, 1 \times 10^{5}$ c.f.u. $\left.\mathrm{ml}^{-1}\right)$ in RPMI 1640 ( $\mathrm{pH} 7.2$ ) buffered with MOPS (165 mM). Two hundred microlitres of this suspension was inoculated per well in 96-well, flatbottomed polystyrene microtitre plates. Media-only blanks were also set up. The plates were incubated at $37{ }^{\circ} \mathrm{C}$ for $24 \mathrm{~h}$ (up to $48 \mathrm{~h}$ for $A$. elegans) and the resulting biofilms were washed twice with PBS, fixed with $200 \mu \mathrm{l} 95 \%$ ethanol at $37{ }^{\circ} \mathrm{C}$ for $15 \mathrm{~min}$ and stained with $200 \mu \mathrm{l}$ $0.1 \%$ safranin for $5 \mathrm{~min}$. Biofilm formation was observed under an inverted microscope (Olympus CKX 41) with a $\times 40$ objective lens and was quantified by measuring the absorbance of the bound safranin, eluted with $200 \mu \mathrm{l} 30 \%$ glacial acetic acid, at $490 \mathrm{~nm}$. Experiments were performed in quadruplicate. The cut-off absorbance was calculated as the mean absorbance of the media-only blanks plus three times their SD $\left(A_{490}=0.075\right)$.

Adhesion kinetics. Two hundred microlitres of the standardized spore suspension was inoculated per well in 96-well, flat-bottomed polystyrene microtitre plates and incubated at $37{ }^{\circ} \mathrm{C}$ for $4,8,12$ and $24 \mathrm{~h}$. The experiments were performed in quadruplicate and mediaonly blanks were set up in parallel. At each time point, the biofilms were washed twice with PBS and were quantified as described previously.

Confocal laser scanning microscopy (CLSM) of biofilms. Three millilitres of the standardized spore suspension was inoculated in $35 \mathrm{~mm}$ Petri dishes and incubated at $37^{\circ} \mathrm{C}$ for $24 \mathrm{~h}$. The biofilms formed were washed twice with $\mathrm{PBS}$, and then stained with wheatgerm agglutinin conjugated to Oregon green (WGA-OG, $0.1 \mathrm{mg} \mathrm{ml}^{-1}$; Invitrogen BioServices India) for $15 \mathrm{~min}$ (Singh et al., 2010) or with concanavalin A conjugated to Alexa Fluor 488 (Con-A, $50 \mu \mathrm{g} \mathrm{ml}^{-1}$ ) and $10 \mu \mathrm{M} \mathrm{FUN-1} \mathrm{(Chandra} \mathrm{et} \mathrm{al.,} \mathrm{2008)} \mathrm{(Invitrogen}$ BioServices India) at $37{ }^{\circ} \mathrm{C}$ for $30 \mathrm{~min}$ in the dark. The biofilms were then washed twice with PBS. CLSM was performed with an LSM 510 Meta (Carl Zeiss MicroImaging) attached to an Axioplan II microscope using a $\times 10 / 0.3$ objective lens.

During CLSM using WGA-OG, HFT 488 was selected as the excitation laser and WGA-OG was detected by fluorescence in the green spectrum using BP505-530. Fungal hyphae were detected by refraction of light in the red spectrum using LP560. NFT 545 was used as the beam splitter and the images were acquired in multitrack mode. For CLSM using dual staining with Con-A/FUN-1, the excitation wavelengths were set to $488 \mathrm{~nm}$ and $543 \mathrm{~nm}$ for Con-A and FUN-1, respectively. NFT 490 (Con-A) and NFT 545 (FUN-1) were used as the beam splitters, and LP 505 (Con-A) and LP 560 (FUN-1) were used as the emission filters. Image analysis was done using $z$-series image stacks from four randomly chosen spots of each biofilm and the biofilm architecture and mean thickness were elucidated using LSM image browser version 4.2.0.121 and ZEN 2009.

Extraction of biofilm matrix. Ten millilitres of the standardized spore suspension was inoculated per flask in five $50 \mathrm{ml}$ polystyrene tissue-culture flasks and incubated at $37{ }^{\circ} \mathrm{C}$ for $24 \mathrm{~h}$. The biofilms formed were washed twice with $\mathrm{PBS}$, flooded with $10 \mathrm{ml}$ sterile MilliQ water per flask and vortexed mildly for $30 \mathrm{~s}$. The suspensions were then pooled and centrifuged at 6000 r.p.m. at $4{ }^{\circ} \mathrm{C}$ for $20 \mathrm{~min}$. The supernatant was collected, filter-sterilized and treated with 2 volumes of chilled $95 \%$ ethanol overnight at $4{ }^{\circ} \mathrm{C}$. The resulting precipitates were collected by centrifugation at 6000 r.p.m. at $4{ }^{\circ} \mathrm{C}$ for $1 \mathrm{~h}$, washed with chilled $95 \%$ ethanol and dried. The EPS matrix was dissolved in water and centrifuged at 6000 r.p.m. at $4{ }^{\circ} \mathrm{C}$ for $10 \mathrm{~min}$. The water-soluble fraction (supernatant) was collected and the waterinsoluble material (pellet) was then dissolved in trichloroacetic acid (TCA). The experiment was performed three times and the matrix was characterized biochemically each time.

Characterization of biofilm matrix. The intracellular enzyme glucose-6-phosphate dehydrogenase (G6PDH) was used as a marker for detecting cell lysis and thereby a contamination of the harvested matrix with cellular components (Flemming \& Wingender, 2010). Ten microlitres of the water-soluble fraction was added to $290 \mu \mathrm{l}$ of 
the assay buffer containing $250 \mathrm{mM}$ glycine buffer ( $\mathrm{pH}$ 7.4), $60 \mathrm{mM}$ glucose 6-phosphate, $20 \mathrm{mM} \mathrm{NADP}$ and $300 \mathrm{mM} \mathrm{MgCl}_{2}$, and incubated at $25{ }^{\circ} \mathrm{C}$ for $5 \mathrm{~min}$. The production of $\mathrm{NADPH}$ was elucidated by measuring the change in absorbance at $340 \mathrm{~nm}$. A molar absorption coefficient of $6.22 \mathrm{mM}^{-1} \mathrm{~cm}^{-1}$ was used and $1 \mathrm{U}$ G6PDH was defined as the enzyme activity catalysing the formation of $1 \mathrm{mmol} \mathrm{NADPH} \mathrm{min}^{-1}$. Protein concentration was determined in the water-soluble fraction by the bicinchoninic acid method (Smith et al., 1985). Total carbohydrates in the water-soluble fraction were determined by the phenol/sulphuric acid method (Dubois et al., 1951). Glucose was quantified in the water-soluble fraction after acid hydrolysis by using a glucose oxidase kit (Sigma-Aldrich) according to the manufacturer's instructions. The presence of amino sugars in the water-soluble fraction was detected by UV spectroscopy (Kumirska et al., 2010). Briefly, the UV absorption of the fractions was scanned over $190-350 \mathrm{~nm}$ in $1 \mathrm{~nm}$ step increments. The firstderivative spectra of the samples were elucidated and compared with those of standard solutions containing $\mathrm{N}$-acetylglucosamine (GlcNAc) and glucosamine (GlcN): GlcNAc only, GlcN only, and GlcNAc and GlcN mixed in different ratios $(4: 1,3: 2,1: 1,2: 3$ and $1: 4)$. The percentage of acetylated and non-acetylated hexosamine in the samples was determined from standard curves of $\lambda_{\min }$ vs percentage GlcNAc as well as calibrated peak height $(H)$ vs percentage GlcNAc. GlcNAc was quantified in the water-soluble and TCAsoluble fractions by enzyme-linked lectinsorbent assay (ELLA) according to the method of Singh et al. (2010), using a standard curve of GlcNAc $(\mu \mathrm{g})$ vs $A_{490}$. GlcN in the water-soluble fraction was determined by its $N$-acetylation using acetic anhydride in methanol (Levvy \& McAllan, 1959), followed by quantification of the GlcNAc formed by ELLA. All experiments were performed in quadruplicate.

Statistical analysis. The two-tailed, unpaired $t$-test was used for comparing the adhesion capacity of test strains versus the media-only blanks.

\section{RESULTS AND DISCUSSION}

Mucorales usually cause acute angioinvasive ROC, pulmonary, gastrointestinal or cutaneous infections in immunocompromised patients (Chakrabarti et al., 2001, 2006, 2009). In addition, these fungi have been implicated in central-venous-catheter-associated fungaemia (Chan-Tack et al., 2005), peritonitis in patients undergoing continuous ambulatory peritoneal dialysis (Branton et al., 1990; Fergie et al., 1992; Nakamura et al., 1989; Nannini et al., 2003; Nayak et al., 2007; Polo et al., 1989; Serna et al., 2003), pleuritis following implantation of drainage catheters (Kimura et al., 2009), endocarditis on native (Mehta et al., 2004; Mitchell et al., 2010) and artificial heart valves (Gubarev et al., 2007; Sanchez-Recalde et al., 1999), osteomyelitis (Chaudhuri et al., 1992; Eaton et al., 1994; Lopes et al., 1995; Meis et al., 1994; Wilkins et al., 2009), and paranasal fungal balls (Goodnight et al., 1993; Kirkpatrick et al., 1979; Lahiri et al., 2001; Robey et al., 2009). Many of these infections are associated with biofilm formation (Costerton et al., 1999; Hall-Stoodley et al., 2004; Loussert et al., 2010) and were reported to exhibit a chronic course (Eaton et al., 1994; Lahiri et al., 2001; Lopes et al., 1995). Furthermore, surface-attached growth of zygomycetes has often been used for industrial purposes (Cao et al., 1997). However, biofilm formation by zygomycetes has not yet been demonstrated. This is believed to be the first study to elucidate the biofilmforming capacity of Rhp. oryzae, L. corymbifera, Rhm. pusillus and A. elegans, and study their adhesion kinetics, biofilm morphology and matrix composition.

\section{Standardization of biofilm formation}

The spore density of Rhp. oryzae, L. corymbifera and Rhm. pusillus in the initial inoculum was found to be important for germination of the adhered spores as well as structural integrity of the biofilms formed (Fig. 1). Whilst very high seeding density (Rhp. oryzae, $1 \times 10^{7}$ and $1 \times 10^{6}$ c.f.u. $\mathrm{ml}^{-1}$; L. corymbifera and Rhm. pusillus, $1 \times 10^{7}, 1 \times 10^{6}$ and $1 \times 10^{5}$ c.f.u. $\mathrm{ml}^{-1}$ ) resulted in poor germination of the adhered spores, low inoculum concentration (Rhp. oryzae, $1 \times 10^{4}$ and $1 \times 10^{3}$ c.f.u. $\mathrm{ml}^{-1}$; L. corymbifera and Rhm. pusillus, $1 \times 10^{3}$ c.f.u. $\mathrm{ml}^{-1}$ ) reduced the hyphal density. Similar results have been previously reported for Aspergillus fumigatus (Mowat et al., 2007), Trichosporon asahii (Di Bonaventura et al., 2006) and various Candida species including C. albicans (Ramage et al., 2009), and may be associated with the production of quorum-sensing molecules (Ramage et al., 2009). Initial seeding densities of $1 \times 10^{5}$ c.f.u. $\mathrm{ml}^{-1}$ (Rhp. oryzae) and $1 \times 10^{4}$ c.f.u. $\mathrm{ml}^{-1}$ (L. corymbifera and $R h m$. pusillus) produced robust, filamentous adherent structures and were selected for further experiments. At these inoculum concentrations, the mean adherence of $R h p$. oryzae, L. corymbifera and Rhm. pusillus on polystyrene plates after $24 \mathrm{~h}$ of incubation was $2.06 \pm 0.02,2.74 \pm 0.29$ and $1.44 \pm 0.05\left(A_{490}\right.$, mean $\left.\pm \mathrm{SD}\right)$, respectively.

Apophysomyces elegans spores germinated at all the three seeding densities tested but adherence and biofilm formation were not detected. No significant difference $(P>0.05)$ was observed between the $A_{490}$ of wells inoculated with $A$. elegans compared to the cut-off $A_{490}$ for biofilm detection $\left[1 \times 10^{7}\right.$ c.f.u. $\mathrm{ml}^{-1}, 0.092 \pm 0.0007$ $(24 \mathrm{~h})$ and $0.091 \pm 0.0 \quad(48 \mathrm{~h}) ; 1 \times 10^{6}$ c.f.u. $\mathrm{ml}^{-1}$, $0.078 \pm 0.0(24 \mathrm{~h})$ and $0.083 \pm 0.0007(48 \mathrm{~h}) ; 1 \times 10^{5}$ c.f.u. $\mathrm{ml}^{-1}, 0.073 \pm 0.018(24 \mathrm{~h})$ and $\left.0.097 \pm 0.013(48 \mathrm{~h})\right] . A$. elegans is usually associated with superficial infections in immunocompetent hosts, although infections in deep tissue have also been described (Chakrabarti et al., 2003, 2010). We reported an upsurge of such A. elegans infections over the past decade in India (Chakrabarti et al., 2003, 2010). These findings indicate that biofilm formation may not play an important role in the pathogenesis of $A$. elegans infections. Species-specific differences in biofilm-forming capacity have also been reported in Candida, and have been correlated with the pathogenesis and the associated risk factors (Hawser \& Douglas, 1994; Kuhn et al., 2002; Li et al., 2003; Ramage et al., 2009).

\section{Adhesion kinetics}

A direct correlation was observed between biomass, quantified by measuring the absorbance of the bound 

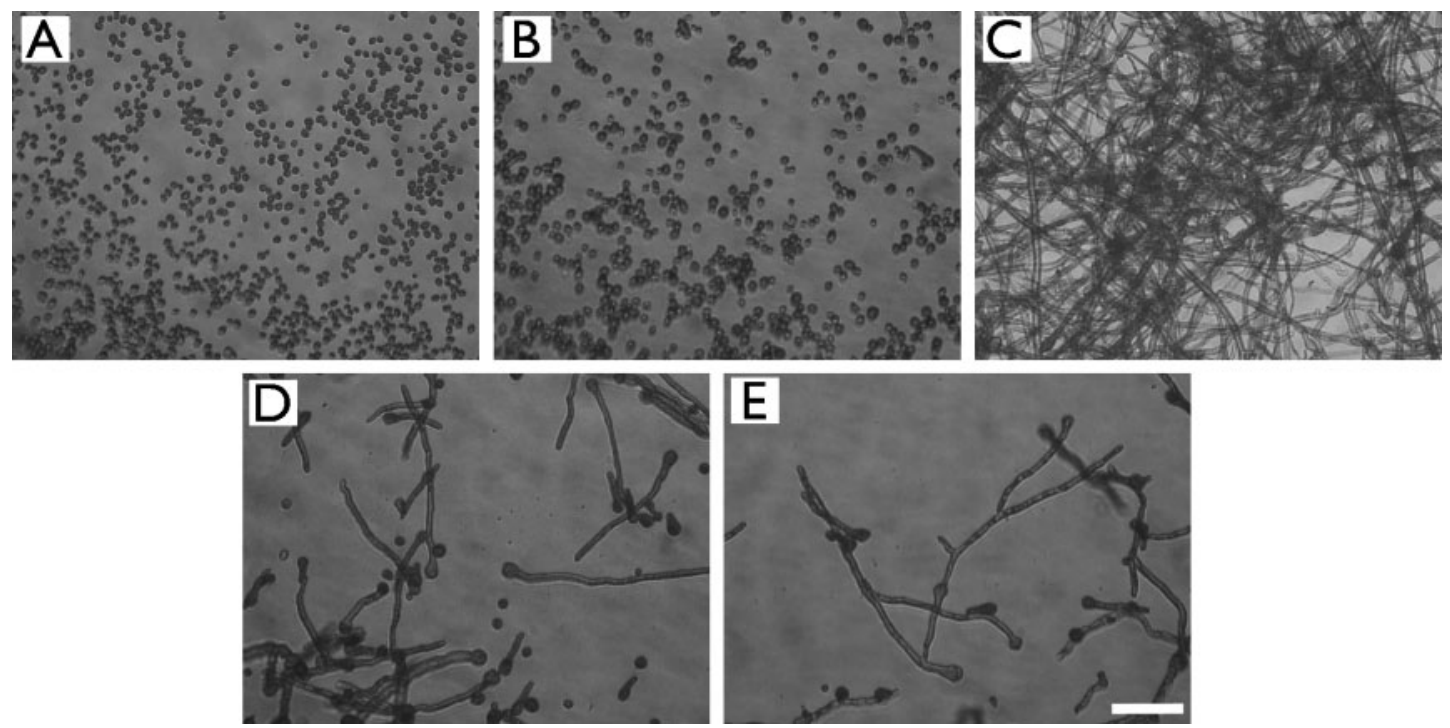

Fig. 1. Effect of seeding density on the development of Rhp. oryzae NCCPF 710004 biofilms after $24 \mathrm{~h}$ at $37^{\circ} \mathrm{C}$. Very high $\left(A, 1 \times 10^{7} ; B, 1 \times 10^{6}\right.$ c.f.u. $\left.\mathrm{ml}^{-1}\right)$ or low spore concentrations $\left(\mathrm{D}, 1 \times 10^{4} ; \mathrm{E}, 1 \times 10^{3}\right.$ c.f.u. $\left.\mathrm{ml}^{-1}\right)$ resulted in poor germination and reduced hyphal density, respectively. An initial seeding density of $1 \times 10^{5}$ c.f.u. $\mathrm{ml}^{-1}$ (C) produced robust, filamentous adherent structures and was selected for further experiments. The images were taken at $\times 40$ using an inverted microscope. Scale bar, $10 \mathrm{~mm}$.

safranin, and hyphal development (Figs 2 and 3). Following initial seeding, the spores adhered to the polystyrene surface and began to swell and germinate in 4-6 h. Hyphae were observed within 8-10 h of incubation. These hyphae formed monolayers by $10-12 \mathrm{~h}$, and then further intertwined and increased in density over the next $12 \mathrm{~h}$. This pattern resembles the kinetics of biofilm formation in Aspergillus fumigatus (Mowat et al., 2007). The intertwining of the mycelial mass provides stability and integrity to the biofilms and is achieved by extensive branching, followed by elongation of the hyphal branches by apical growth (Chandrasekar \& Manavathu, 2008; Mowat et al., 2009).

\section{CLSM of biofilms}

Microbial biofilms are characterized by the presence of surface-attached cells enmeshed in a self-produced gelatinous matrix made primarily of polysaccharides (Costerton et al., 1999; Hall-Stoodley et al., 2004). This matrix, also termed slime or EPS, forms a scaffold for the threedimensional architecture of the biofilm (Flemming \& Wingender, 2010; Hall-Stoodley et al., 2004). It provides stability to the biofilm structure, helps in adherence as well as in trapping the nutrients, and also protects the biofilm cells from desiccation, UV radiation, protozoan grazers, antimicrobials and host immune defences (Flemming \& Wingender, 2010; Hall-Stoodley et al., 2004).

To detect the presence of polysaccharide matrix and elucidate the biofilm architecture, confocal microscopy was performed using the plant-based lectins WGA and concanavalin A. These markers bind to GlcNAc (WGA) (Singh et al., 2010), glucose and mannose (concanavalin A) (Chandra et al., 2008), and therefore detect these specific residues in the hyphae and the matrix, if any. Individual fungal hyphae were also detected via the red light refracted by the cells (WGA-OG staining) or FUN-1 (Con-A/FUN-1 staining), and the images obtained were compared with WGA-OG or Con-A fluorescence for differentiation between the binding of WGA or Con-A to the hyphae and the matrix.

Phase-contrast images of the confocal micrographs revealed a haze-like film, suggestive of a polysaccharide matrix, covering the fungal hyphae in the biofilms (Fig. 4). CLSM images also indicated the presence of highly intertwined mycelia mass, with WGA-OG staining many inter-hyphal regions as well (Fig. 4). These results demonstrate the existence of an exopolysaccharide matrix in Rhp. oryzae, L. corymbifera and Rhm. pusillus biofilms and further satisfy the criteria proposed for detecting biofilm formation in filamentous fungi (Harding et al., 2009). Also, the staining of many inter-hyphal regions with WGA-OG suggests the presence of GlcNAc in the matrix. In contrast, Con-A detected the fungal hyphae but interhyphal regions were not significantly stained with this marker, indicating that glucans and mannans were not a major component of the matrix. This was further confirmed by biochemical characterization of EPS extracted from the biofilms. The thickness of Rhp. oryzae, L. corymbifera and Rhm. pusillus biofilms was $109.67 \pm$ $10.02 \mu \mathrm{m}, 242 \pm 23.07 \mu \mathrm{m}$ and $197 \pm 9.0 \mu \mathrm{m}$ (mean \pm SD), respectively. 

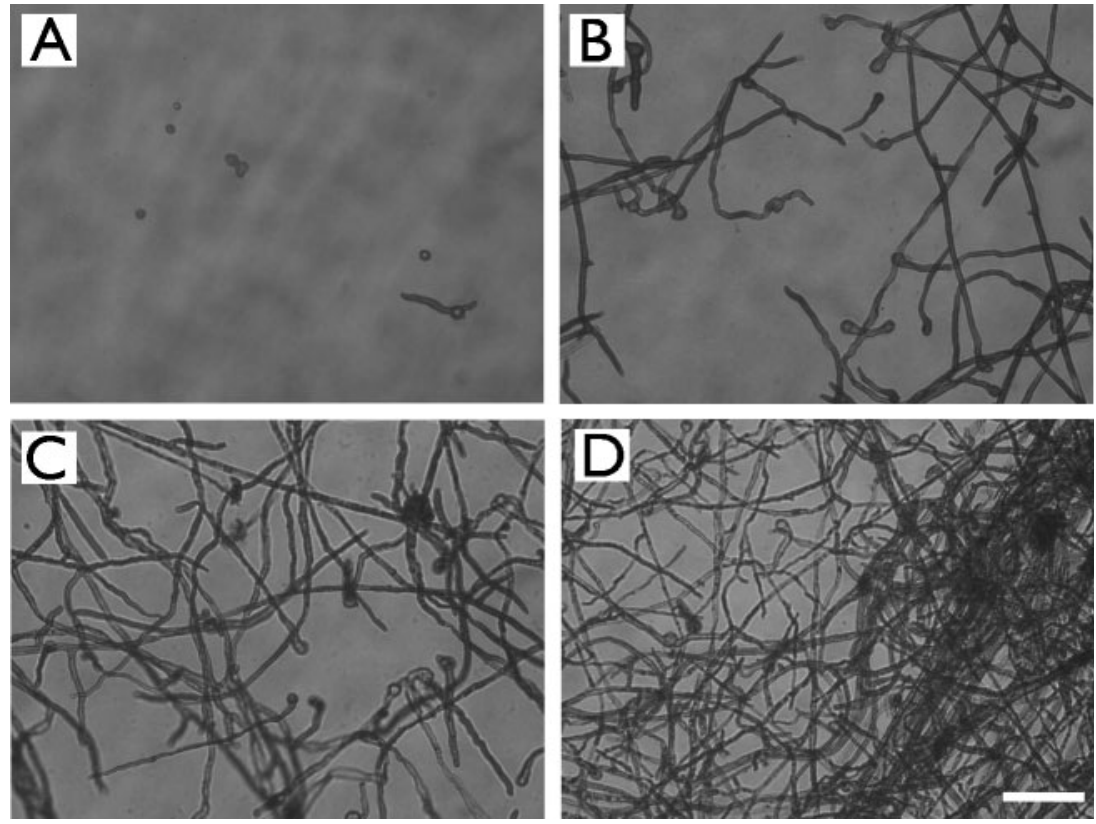

Fig. 2. Hyphal development during adhesion of Rhp. oryzae NCCPF 710004 on 96-well, flatbottomed polystyrene microtitre plates. The plates were incubated at $37^{\circ} \mathrm{C}$ for $4 \mathrm{~h}(\mathrm{~A}), 8 \mathrm{~h}$ (B), $12 \mathrm{~h}(\mathrm{C})$ and $24 \mathrm{~h}(\mathrm{D})$. The images were taken at $\times 40$ using an inverted microscope. Scale bar, $10 \mathrm{~mm}$.

\section{Characterization of the biofilm matrix}

EPS has often been called the 'dark matter' of biofilms, owing to the large range of biopolymers it may contain, and the difficulty in analysing them (Flemming \& Wingender, 2010). It accounts for a major component of the biofilm biomass and consists primarily of polysaccharides, although proteins (including many enzymes), lipids and extracellular DNA may also be present (Flemming \& Wingender, 2010).

G6PDH activity was not detected in the matrices extracted from Rhp. oryzae, L. corymbifera and Rhm. pusillus biofilms,

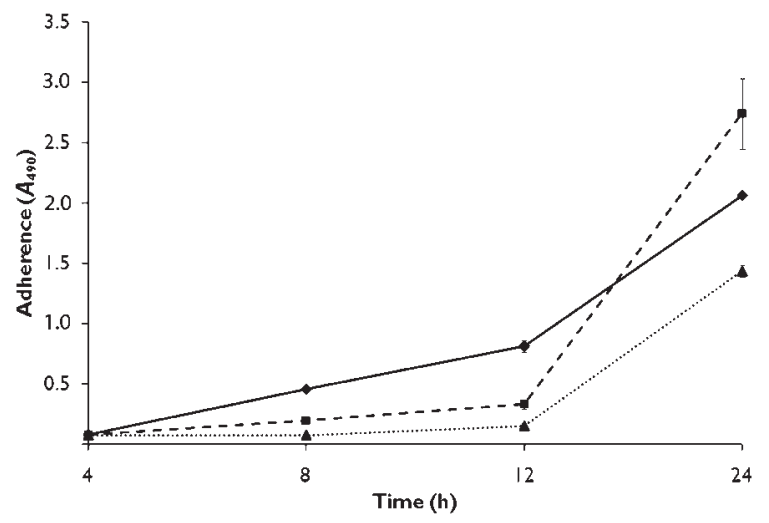

Fig. 3. Adhesion kinetics of Rhp. oryzae NCCPF 710004 L. corymbifera NCCPF 700002 (口- - - $\mathbf{0}$ ) and Rhm. pusillus NCCPF $720004(\mathbf{\Delta} \cdots \mathbf{\Delta})$ on 96-well, flat-bottomed polystyrene microtitre plates. The plates were incubated at $37{ }^{\circ} \mathrm{C}$ for $4,8,12$ and $24 \mathrm{~h}$ (note the non-linear time scale). Data are represented as $A_{490}$. Experiments were performed in quadruplicate. Error bars indicate standard deviation (not shown where smaller than symbols). confirming an absence of contaminating cellular components. Hexosamine and $\mathrm{N}$-acetylhexosamine constituted 93.4-95.6\% and 4.4-6.6\%, respectively, of the amino sugars in the water-soluble EPS fraction. GlcN was found to be the primary component of Rhp. oryzae, L. corymbifera and Rhm. pusillus biofilm matrix, constituting $745.38 \pm 115.25$, $822.20 \pm 178.99$ and $803.94 \pm 135.43 \mu \mathrm{g} \quad(\mathrm{mg} \quad \text { EPS })^{-1}$ (mean $\pm \mathrm{SD}$ ), respectively. In contrast, GlcNAc constituted $43.49 \pm 6.72,47.97 \pm 10.44$ and $46.91 \pm 7.90 \mu \mathrm{g}(\mathrm{mg} \mathrm{EPS})^{-1}$ (mean $\pm \mathrm{sD}$ ) in Rhp. oryzae, L. corymbifera and Rhm. pusillus biofilms, respectively. These results suggest the presence of the chitin-derivative chitosan, a partially acetylated $\beta-1,4-$ linked GlcN polymer, which is usually soluble in water at a high degree of deacetylation (Kumirska et al., 2010). In contrast to other fungi, chitin and chitosan constitute a major component of the cell wall in zygomycetes (BartnickiGarcia, 1968). Chitosan cements the cell wall, protects chitin from enzymic attack and also adsorbs ionic material by salt or complex formation (Bartnicki-Garcia, 1968). The content of this aminopolysaccharide in zygomycetes' cell wall may be up to three times the amount of chitin (Bartnicki-Garcia, 1968). A similar partially deacetylated $\beta-1,6$-linked GlcNAc polymer termed polysaccharide intercellular adhesin (PIA) is the primary component of Staphylococcus aureus and Staphylococcus epidermidis biofilm matrix and it mediates cell-to-cell interaction in these bacteria (Singh et al., 2010). Hexosamine has also been reported as an important component of EPS in Candida tropicalis biofilms (AlFattani \& Douglas, 2006).

The high concentration of amino sugars interfered with the determination of carbohydrates by the phenol/sulphuric acid method. Upon reaction with this reagent, the samples exhibited a peak absorbance at $405 \mathrm{~nm}$, compared to the usual $490 \mathrm{~nm}$ observed in sugars. Glucose content was therefore determined in the water-soluble fraction using a 

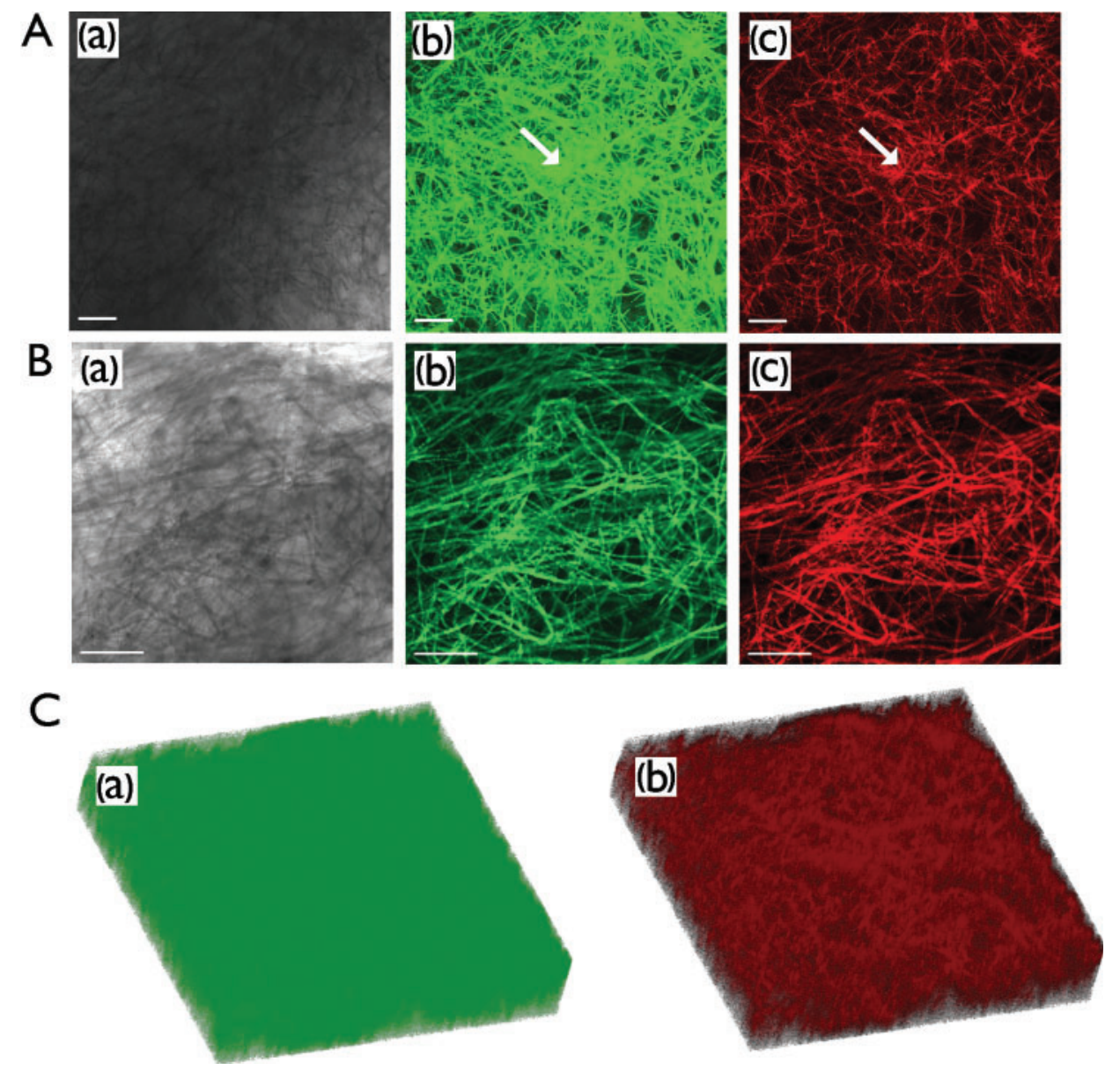

Fig. 4. Phase-contrast $(\mathrm{Aa}$ and $\mathrm{Ba}$ ) and confocal laser scanning micrographs ( $\mathrm{Bb}$ and $\mathrm{Ac}, \mathrm{Bb}$ and $\mathrm{Bc}, \mathrm{Ca}$ and $\mathrm{Cb})$ of $R h m$. pusillus NCCPF 720004 biofilms. (A) WGA-OG staining. WGA-OG (Ab) was used to detect GlcNAc in the fungal hyphae and the biofilm matrix. Individual fungal hyphae were also detected via the red light refracted by the cells (Ac) and the images obtained were compared with WGA-OG fluorescence for differentiation between the binding of WGA to the hyphae and the matrix. The arrow indicates a representative inter-hyphal region stained by WGA-OG. Scale bars, $100 \mu \mathrm{m}$; (B) Con-A and FUN-1 staining. Con- $\mathrm{A}(\mathrm{Bb})$ was used to detect glucose and mannose in the fungal hyphae as well as in the biofilm matrix, if any. Individual fungal hyphae were also detected via FUN-1 $(\mathrm{Bc})$ and the images obtained were compared with Con-A fluorescence for differentiation between the binding of Con- $A$ to the hyphae and the matrix, if any. Scale bars, $100 \mu \mathrm{m}$. (C) Three-dimensional reconstruction of biofilms after staining with WGA-OG. (Ca) Detection of GlcNAc in the hyphae and matrix with WGA-OG; (Cb) detection of hyphae by collecting the red-refracted light.

glucose oxidase kit. Although glucose constitutes $32-74 \%$ of the biofilm matrix in Aspergillus fumigatus (Beauvais et al., 2007) and Candida species (Al-Fattani \& Douglas, 2006; Silva et al., 2009), it accounted for only a small proportion of the biofilm-matrix weight in the Mucorales that we studied. Rhp. oryzae, L. corymbifera and Rhm. pusillus biofilm EPS contained $7.42 \pm 0.92,7.92 \pm 1.20$ and $7.17 \pm 0.71 \mu$ g glucose $(\mathrm{mg} \mathrm{EPS})^{-1}$ (mean $\left.\pm \mathrm{sD}\right)$, respectively. Proteins were also detected in the matrix preparations, constituting $2.23 \pm 0.10$, $7.70 \pm 0.31$ and $3.17 \pm 0.61 \mu \mathrm{g}(\mathrm{mg} \mathrm{EPS})^{-1}($ mean $\pm \mathrm{SD})$ in $R h$. oryzae, L. corymbifera and Rhm. pusillus, respectively. However, these results probably underestimate the protein content of the slime. The solubilized matrix harvested from the biofilms was concentrated using ethanol, an organic solvent which preferentially precipitates polysaccharides
(Flemming \& Wingender, 2010). The protein content of the suspensions before ethanol precipitation was about sevenfold higher than that of the precipitated EPS.

The TCA-soluble EPS fraction was processed for the detection of chitin, a $\beta$-1,4-linked GlcNAc polymer insoluble in water and many acids (Kumirska et al., 2010), and its monomer GlcNAc was quantified by ELLA. The concentration of GlcNAc in the TCA-soluble fraction of Rhp. oryzae, L. corymbifera and Rhm. pusillus biofilm matrix was $59.43 \pm 0.80,74.28 \pm 8.09$ and $56.89 \pm 4.40 \mu \mathrm{g}(\mathrm{mg} \text { EPS })^{-1}$ (mean $\pm \mathrm{SD}$ ), respectively.

Thus, the extracellular matrix in Rhp. oryzae, L. corymbifera and Rhm. pusillus biofilms is primarily composed of amino sugars (GlcN and GlcNAc), with glucose and proteins also 
being present in small amounts. By contrast, glucose is the major component of Candida and Aspergillus fumigatus biofilms (Al-Fattani \& Douglas, 2006; Baillie \& Douglas, 2000; Beauvais et al., 2007; Lal et al., 2010; Silva et al., 2009). In A. fumigatus biofilms, the EPS consists of glucose $(74 \%)$, mannitol $(18 \%)$, trehalose $(3 \%)$, glycerol $(5 \%)$, and melanin and proteins (2\%) (Beauvais et al., 2007). Immunolabelling studies have further revealed the presence of galactomannan, galactosaminogalactan and $\alpha-1,3$ glucans (Beauvais et al., 2007; Loussert et al., 2010). C. albicans biofilms usually contain glucose (16-32.2\%), hexosamine $(3.3 \%)$, proteins $(5 \%)$, phosphorus $(0.5 \%)$ and uronic acid $(0.1 \%)$ as well as mannose, rhamnose and galactose in the matrix (Al-Fattani \& Douglas, 2006; Baillie \& Douglas, 2000; Lal et al., 2010). However, C. tropicalis biofilm matrix comprises mainly hexosamine (27.4\%), with smaller amounts of other carbohydrates (3.3\%, including $0.5 \%$ glucose), protein $(3.3 \%)$ and phosphorus $(0.2 \%)$ (Al-Fattani \& Douglas, 2006).

In conclusion, our results reveal the biofilm-forming potential of Rhp. oryzae, L. corymbifera and Rhm. pusillus, but not A. elegans. At appropriate seeding densities, these fungi produced robust, highly intertwined, filamentous, adherent structures that were encased in an extracellular matrix composed primarily of GlcN and GlcNAc. Although Mucorales are usually implicated in angio-invasive infections, biofilm formation may be involved in the pathogenesis of paranasal fungal balls, endocarditis, osteomyelitis and catheter-based infections caused by these pathogens. It may also be important for the survival of these saprophytic fungi in the environment (Ramage et al., 2009).

\section{ACKNOWLEDGEMENTS}

This work was supported by funding from the Indian Council of Medical Research (ICMR). We thank Dr Alok Mondal, Scientist Gr. IV(5) and Mr Deepak Bhatt, Technical assistant Gr III(1), Institute of Microbial Technology (IMTECH), Chandigarh, India, for help with the CLSM.

\section{REFERENCES}

Al-Fattani, M. A. \& Douglas, L. J. (2006). Biofilm matrix of Candida albicans and Candida tropicalis: chemical composition and role in drug resistance. J Med Microbiol 55, 999-1008.

Baillie, G. S. \& Douglas, L. J. (2000). Matrix polymers of Candida biofilms and their possible role in biofilm resistance to antifungal agents. J Antimicrob Chemother 46, 397-403.

Bartnicki-Garcia, S. (1968). Cell wall chemistry, morphogenesis, and taxonomy of fungi. Annu Rev Microbiol 22, 87-108.

Beauvais, A., Schmidt, C., Guadagnini, S., Roux, P., Perret, E., Henry, C., Paris, S., Mallet, A., Prévost, M. C. \& Latgé, J. P. (2007). An extracellular matrix glues together the aerial-grown hyphae of Aspergillus fumigatus. Cell Microbiol 9, 1588-1600.

Branton, M. H., Johnson, S. C., Brooke, J. D. \& Hasbargen, J. A. (1990). Peritonitis due to Rhizopus in a patient undergoing continuous ambulatory peritoneal dialysis. Rev Infect Dis 13, $19-21$.
Cao, N., Du, J., Chen, C., Gong, C. S. \& Tsao, G. T. (1997). Production of fumaric acid by immobilized Rhizopus using rotary biofilm contactor. Appl Biochem Biotechnol 63-65, 387-394.

Chakrabarti, A., Das, A., Sharma, A., Panda, N., Das, S., Gupta, K. L. \& Sakhuja, V. (2001). Ten years' experience in zygomycosis at a tertiary care centre in India. J Infect 42, 261-266.

Chakrabarti, A., Ghosh, A., Prasad, G. S., David, J. K., Gupta, S., Das, A., Sakhuja, V., Panda, N. K., Singh, S. K. \& other authors (2003). Apophysomyces elegans: an emerging zygomycete in India. $J$ Clin Microbiol 41, 783-788.

Chakrabarti, A., Das, A., Mandal, J., Shivaprakash, M. R., George, V. K., Tarai, B., Rao, P., Panda, N., Verma, S. C. \& Sakhuja, V. (2006). The rising trend of invasive zygomycosis in patients with uncontrolled diabetes mellitus. Med Mycol 44, 335-342.

Chakrabarti, A., Chatterjee, S. S., Das, A., Panda, N., Shivaprakash, M. R., Kaur, A., Varma, S. C., Singhi, S., Bhansali, A. \& Sakhuja, V. (2009). Invasive zygomycosis in India: experience in a tertiary care hospital. Postgrad Med J 85, 573-581.

Chakrabarti, A., Shivaprakash, M. R., Curfs-Breuker, I., Baghela, A., Klaassen, C. H. \& Meis, J. F. (2010). Apophysomyces elegans: epidemiology, amplified fragment length polymorphism typing, and in vitro antifungal susceptibility pattern. J Clin Microbiol 48, 45804585.

Chan-Tack, K. M., Nemoy, L. L. \& Perencevich, E. N. (2005). Central venous catheter-associated fungemia secondary to mucormycosis. Scand J Infect Dis 37, 925-927.

Chandra, J., Mukherjee, P. K. \& Ghannoum, M. A. (2008). In vitro growth and analysis of Candida biofilms. Nat Protoc 3, 1909-1924.

Chandrasekar, P. H. \& Manavathu, E. K. (2008). Do Aspergillus species produce biofilm? Future Microbiol 3, 19-21.

Chaudhuri, R., McKeown, B., Harrington, D., Hay, R. J., Bingham, J. B. \& Spencer, J. D. (1992). Mucormycosis osteomyelitis causing avascular necrosis of the cuboid bone: MR imaging findings. AJR Am J Roentgenol 159, 1035-1037.

Costerton, J. W., Stewart, P. S. \& Greenberg, E. P. (1999). Bacterial biofilms: a common cause of persistent infections. Science 284, 13181322.

Di Bonaventura, G., Pompilio, A., Picciani, C., lezzi, M., D’Antonio, D. \& Piccolomini, R. (2006). Biofilm formation by the emerging fungal pathogen Trichosporon asahii: development, architecture, and antifungal resistance. Antimicrob Agents Chemother 50, 32693276.

Dubois, M., Gilles, K., Hamilton, J. K., Rebers, P. A. \& Smith, F. (1951). A colorimetric method for the determination of sugars. Nature 168, 167.

Eaton, M. E., Padhye, A. A., Schwartz, D. A. \& Steinberg, J. P. (1994). Osteomyelitis of the sternum caused by Apophysomyces elegans. J Clin Microbiol 32, 2827-2828.

Fergie, J. E., Fitzwater, D. S., Einstein, P. \& Leggiadro, R. J. (1992). Mucor peritonitis associated with acute peritoneal dialysis. Pediatr Infect Dis J 11, 498-500.

Flemming, H. C. \& Wingender, J. (2010). The biofilm matrix. Nat Rev Microbiol 8, 623-633.

Goodnight, J., Dulguerov, P. \& Abemayor, E. (1993). Calcified Mucor fungus ball of the maxillary sinus. Am J Otolaryngol 14, 209-210.

Gubarev, N., Separovic, J., Gasparovic, V. \& Jelic, I. (2007). Successful treatment of mucormycosis endocarditis complicated by pulmonary involvement. Thorac Cardiovasc Surg 55, 257-258.

Hall-Stoodley, L., Costerton, J. W. \& Stoodley, P. (2004). Bacterial biofilms: from the natural environment to infectious diseases. Nat Rev Microbiol 2, 95-108. 
Harding, M. W., Marques, L. L., Howard, R. J. \& Olson, M. E. (2009). Can filamentous fungi form biofilms? Trends Microbiol 17, 475-480.

Hawser, S. P. \& Douglas, L. J. (1994). Biofilm formation by Candida species on the surface of catheter materials in vitro. Infect Immun 62, 915-921.

Kimura, M., Udagawa, S., Makimura, K., Satoh, K., Toyazaki, N. \& Ito, H. (2009). Isolation and identification of Rhizomucor pusillus from pleural zygomycosis in an immunocompetent patient. Med Mycol 47, 869-873.

Kirkpatrick, M. B., Pollock, H. M., Wimberley, N. E., Bass, J. B., Davidson, J. R. \& Boyd, B. W. (1979). An intracavitary fungus ball composed of Syncephalastrum. Am Rev Respir Dis 120, 943-947.

Kuhn, D. M., Chandra, J., Mukherjee, P. K. \& Ghannoum, M. A. (2002). Comparison of biofilms formed by Candida albicans and Candida parapsilosis on bioprosthetic surfaces. Infect Immun 70, 878-888.

Kumirska, J., Czerwicka, M., Kaczyński, Z., Bychowska, A., Brzozowski, K., Thöming, J. \& Stepnowski, P. (2010). Application of spectroscopic methods for structural analysis of chitin and chitosan. Mar Drugs 8, 1567-1636.

Lahiri, T. K., Agarwal, D., Reddy, G. E. \& Bajoria, A. (2001). Pulmonary mucoraceous fungal ball. Indian J Chest Dis Allied Sci 43, 107-110.

Lal, P., Sharma, D., Pruthi, P. \& Pruthi, V. (2010). Exopolysaccharide analysis of biofilm-forming Candida albicans. J Appl Microbiol 109, 128-136.

Levvy, G. A. \& McAllan, A. (1959). The $N$-acetylation and estimation of hexosamines. Biochem J 73, 127-132.

Li, X., Yan, Z. \& Xu, J. (2003). Quantitative variation of biofilms among strains in natural populations of Candida albicans. Microbiology 149, 353-362.

Lopes, J. O., Pereira, D. V., Streher, L. A., Fenalte, A. A., Alves, S. H. \& Benevenga, J. P. (1995). Cutaneous zygomycosis caused by Absidia corymbifera in a leukemic patient. Mycopathologia 130, 89-92.

Loussert, C., Schmitt, C., Prevost, M. C., Balloy, V., Fadel, E., Philippe, B., Kauffmann-Lacroix, C., Latgé, J. P. \& Beauvais, A. (2010). In vivo biofilm composition of Aspergillus fumigatus. Cell Microbiol 12, 405-410.

Mehta, N. N., Romanelli, J. \& Sutton, M. G. (2004). Native aortic valve vegetative endocarditis with Cunninghamella. Eur J Echocardiogr 5, 156-158.

Meis, J. F., Kullberg, B. J., Pruszczynski, M. \& Veth, R. P. (1994). Severe osteomyelitis due to the zygomycete Apophysomyces elegans. J Clin Microbiol 32, 3078-3081.

Mitchell, M. E., McManus, M., Dietz, J., Camitta, B. M., Szabo, S. \& Havens, P. (2010). Absidia corymbifera endocarditis: survival after treatment of disseminated mucormycosis with radical resection of tricuspid valve and right ventricular free wall. $J$ Thorac Cardiovasc Surg 139, e71-e72.

Mowat, E., Butcher, J., Lang, S., Williams, C. \& Ramage, G. (2007). Development of a simple model for studying the effects of antifungal agents on multicellular communities of Aspergillus fumigatus. J Med Microbiol 56, 1205-1212.

Mowat, E., Lang, S., Williams, C., McCulloch, E., Jones, B. \& Ramage, G. (2008). Phase-dependent antifungal activity against Aspergillus fumigatus developing multicellular filamentous biofilms. J Antimicrob Chemother 62, 1281-1284.

Mowat, E., Williams, C., Jones, B., McChlery, S. \& Ramage, G. (2009). The characteristics of Aspergillus fumigatus mycetoma development: is this a biofilm? Med Mycol 47 (Suppl. 1), S120-S126.

Nakamura, M., Weil, W. B., Jr \& Kaufman, D. B. (1989). Fatal fungal peritonitis in an adolescent on continuous ambulatory peritoneal dialysis: association with deferoxamine. Pediatr Nephrol 3, 80-82.

Nannini, E. C., Paphitou, N. I. \& Ostrosky-Zeichner, L. (2003). Peritonitis due to Aspergillus and zygomycetes in patients undergoing peritoneal dialysis: report of 2 cases and review of the literature. Diagn Microbiol Infect Dis 46, 49-54.

Nayak, S., Satish, R., Gokulnath, Savio, J. \& Rajalakshmi, T. (2007). Peritoneal mucormycosis in a patient on CAPD. Perit Dial Int 27, 216-217.

Pierce, C. G., Uppuluri, P., Tristan, A. R., Wormley, F. L., Jr, Mowat, E., Ramage, G. \& Lopez-Ribot, J. L. (2008). A simple and reproducible 96-well plate-based method for the formation of fungal biofilms and its application to antifungal susceptibility testing. Nat Protoc 3, 14941500.

Polo, J. R., Luño, J., Menarguez, C., Gallego, E., Robles, R. \& Hernandez, P. (1989). Peritoneal mucormycosis in a patient receiving continuous ambulatory peritoneal dialysis. Am J Kidney Dis 13, 237-239.

Ramage, G., Mowat, E., Jones, B., Williams, C. \& Lopez-Ribot, J. (2009). Our current understanding of fungal biofilms. Crit Rev Microbiol 35, 340-355.

Robey, A. B., O’Brien, E. K., Richardson, B. E., Baker, J. J., Poage, D. P. \& Leopold, D. A. (2009). The changing face of paranasal sinus fungus balls. Ann Otol Rhinol Laryngol 118, 500-505.

Sanchez-Recalde, A., Merino, J. L., Dominguez, F., Mate, I., Larrea, J. L. \& Sobrino, J. A. (1999). Successful treatment of prosthetic aortic valve mucormycosis. Chest 116, 1818-1820.

Serna, J. H., Wanger, A. \& Dosekun, A. K. (2003). Successful treatment of mucormycosis peritonitis with liposomal amphotericin $\mathrm{B}$ in a patient on long-term peritoneal dialysis. Am J Kidney Dis 42, E14-E17.

Silva, S., Henriques, M., Martins, A., Oliveira, R., Williams, D. \& Azeredo, J. (2009). Biofilms of non-Candida albicans Candida species: quantification, structure and matrix composition. Med Mycol 47, 681-689.

Singh, R., Ray, P., Das, A. \& Sharma, M. (2010). Enhanced production of exopolysaccharide matrix and biofilm by a menadione-auxotrophic Staphylococcus aureus small-colony variant. J Med Microbiol 59, 521527.

Smith, P. K., Krohn, R. I., Hermanson, G. T., Mallia, A. K., Gartner, F. H., Provenzano, M. D., Fujimoto, E. K., Goeke, N. M., Olson, B. J. \& Klenk, D. C. (1985). Measurement of protein using bicinchoninic acid. Anal Biochem 150, 76-85.

Wilkins, R. M., Hahn, D. B. \& Blum, R. (2009). Bread mold osteomyelitis in the femur. Orthopedics 32, 362-365.

Edited by: I. J. Van der Klei 